\title{
Hierarchical Control System for DC Microgrid
}

\author{
Yaning Yuan \\ State Grid Jibei Electric Power Co. Ltd. Skill Training \\ Center \\ Baoding, China \\ E-mail: yuanyaning1990@126.com
}

\author{
Sen Yang \\ Shenyang Institute of Engineering \\ Shenyang, China \\ E-mail: yzlbddx@163.com
}

\begin{abstract}
In order to enhance the plug and play function of new energy power generation in DC microgrid, to increase the utilization of renewable energy and to improve the performance of DC bus voltage, a hierarchical control strategy of DC microgrid is proposed. This hierarchical control strategy is composed of two levels. Distributed control is adopted for new energy power generation and energy storage unit controlled by voltage stabilization strategy to guarantee the stability of DC bus voltage in the primary control level. Secondary control level is employed to restore the voltage deviation caused by the primary control, using bidirectional vector decoupling control and solves the problem of bidirectional power flow with the grid. The detailed theoretical analysis and design method for each control level is also realized. Comprehensive simulation results indicate that the system based on new control method is stable and effective.
\end{abstract}

Keywords-DC Microgrid; Hierarchical Control Strategy; Maximum Power Point Tracking; Voltage Stabilization; Bidirectional AC/DC Converter

\section{INTRODUCTION}

Distributed clean energy power generation has the notable features of stochastic volatility and intermittence, and the safe and stable operation of traditional power system will be impacted and affected due to the large scale access to the grid [1-2]. In order to give full play to the benefits and value of distributed generation, and weaken the negative impacts on power network, R. H. Lasseter of American Wisconsin University proposed the concept of microgrid [3-4]. Currently, at home and abroad, there are three structures of microgrid: AC microgrid, DC micro grid and AC / DC hybrid microgrid, and the AC microgrid is in the majority[5-8]. The microgrid commonly contains distributed generation, energy storage system, load and control system [9-14]. The DC system can reduce power converter series and improve the overall efficiency, without considering the problem such as frequency stability, reactive power, skin effect and AC loss, compared with the AC system [15]. And with the rapid development of the new load such as computer, household appliances, inverter, switch power supply, communication equipment, electric vehicles and a variety of electronic equipment, DC microgrid will have broader prospects.

As a result of the distributed characteristics of DG in the DC microgrid system, a large number of control data, flexible and variable control mode, and considering the system expansion and the ability of detaching while the host and other peripherals are in operation, therefore, the research on the stability control of DC microgrid becomes the focus. Salomonsson D. proposed increasing a central controller (Data Center) in the system to realize the coordinated control between the micro generations [16]. The method achieves the control of the micro power supply based on the bus communication, so it depends on the reliability of transmission strongly. At the same time, the control mode of the judgment, centralized scheduling by control center can't realize flexible and effective control. Josep M. proposed hierarchical control method [17]. The system is divided into a plurality of layers of control. The respective control strategy is used in each layer of the control, but the method cannot achieve the optimal control mode of renewable energy output priority. John S. presented the distributed control structure based on DC bus signal, but it didn't come with power distribution of multiple micro sources at a voltage level and can't realize the bidirectional flow with the grid system [18-19]. In this paper, a hierarchical control strategy is proposed based on the DC microgrid of solar and storage.

\section{STRUCTURE OF THE SYSTEM}

The emergence of DC microgrid has brought many conveniences to the distributed generation of renewable energy. The DC microgrid is mainly composed of bidirectional converter, solar, energy storage device, DC bus and DC load. Fig. 1 is the topology of the DC microgrid.

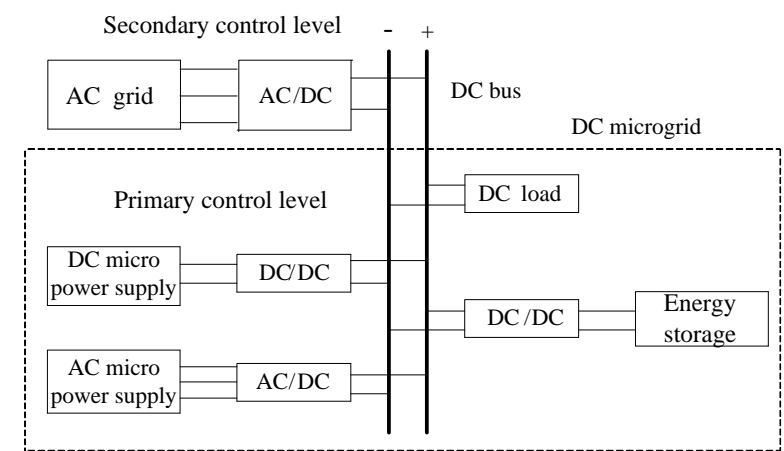

Figure 1. The topology of the DC microgrid.

\section{THE PRIMARY CONTROL LEVEL}

\section{A. PV MPPT Control Strategy}

Maximum power point tracking (MPPT) is a track control method that directly or indirectly exploits the work status of PV to determine its maximum power point. 
During the tracking control, although the collection signal is the instantaneous power value of the photovoltaic (PV) array, the final control signal is the output voltage of the solar systems [20-21].

Fig. 2 shows the maximum power point tracking (MPPT) control system block diagram. PV modules provide DC voltage through the Boost circuit. The MPPT controller system tracks the maximum power point of $\mathrm{PV}$ modules by small-disturbance method, and then generates control signals. In order to make the maximum voltage of $\mathrm{PV}$ modules maintained at the maximu mower point, the duty cycle $\mathrm{D}$ of the Boost circuit switch $\mathrm{T}$ and the input voltage $U_{s}$ are regulated by the PWM drive signal. So, the $\mathrm{PV}$ modules always work in the best condition, and the maximu $m$ power output makes sure the optimal utilization of energy.

\section{B. Voltage Control Strategy}

The intermittent of the renewable energy lead to fluctuations in the DC bus voltage. In order to stabilize DC bus voltage, the storage battery is connected to the microgrid by a bi-d irectional DC-DC converter. According to the real-time dynamic testing, the system can regulate the battery operation mode and maintain the stability of the DC bus voltage.

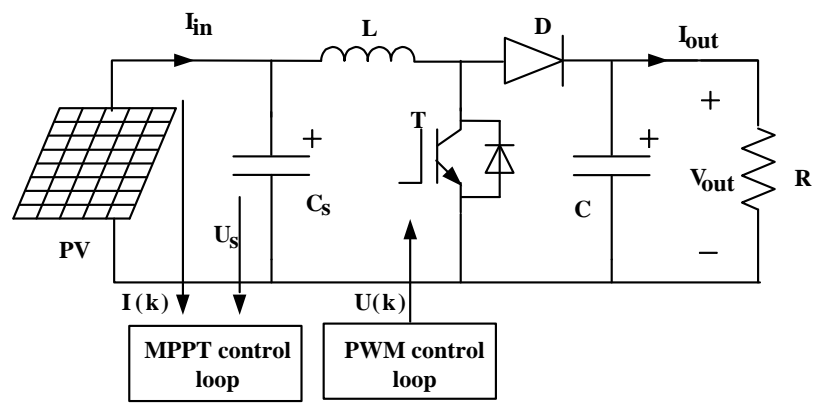

Figure 2. MPPT control system block diagram.

The bi-directional DC-DC converter circuit is shown in Fig. 3. Switch drivers work in complementary PWM mode. That is, whether the converter operates in Boost mode or Buck mode, switch control signals $\mathrm{T} 1$ and $\mathrm{T} 2$ are complementary. When T1 is high level, T2 is low level, and vice versa. Furthermore, to avoid the bridge arms breakover, the dead time between two switche tubes is set necessarily. In the practical application, selecting the integrated half-bridge IGBT module can simplify the structure and make it easy to implement.

The system implements the function of electric vehicle batteries charging and discharging by voltage smooth control strategy. As shown in Fig. 4, double closed loop control method is used in the bi-directional DC-DC converter. The DC bus rated voltage is set as $750 \mathrm{~V}$. The difference between the DC bus voltage value and the rated voltage value is the input signal of PI regulator. The battery reference current is obtained from the PI regulator. The inner current control loop measures the actual current to track the reference current value offered by the outer loop. After comparing the actual current and the reference current, the signal go into the PI regulator and then the PWM signal is generated by the PWM controller, which controls the bi-directional DC-DC converter.

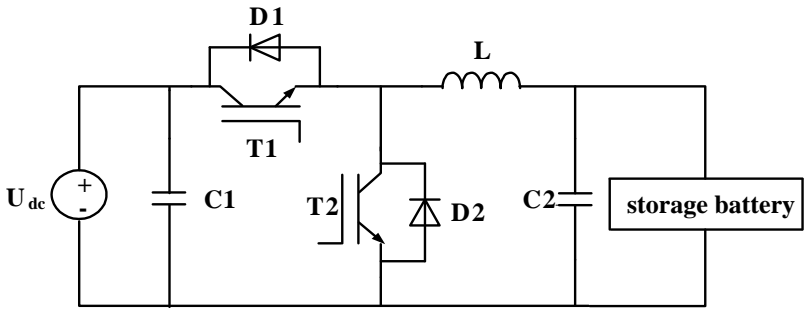

Figure 3. The bi-directional DC / DC circuit
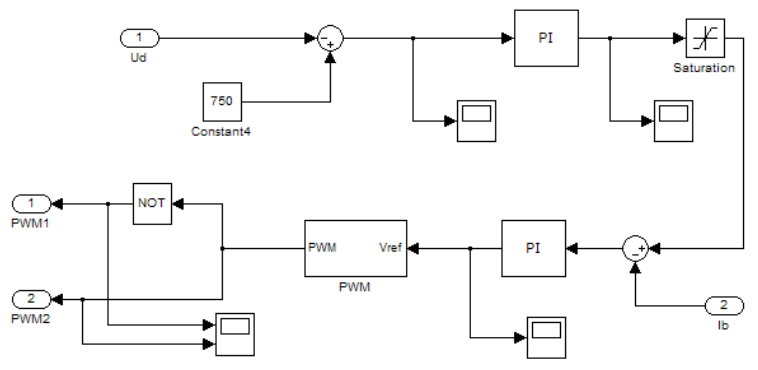

Figure 4. The simulation model of voltage stabilization control

\section{SECONDARY CONTROL LEVEL}

The solar power is often influenced by natural conditions. And the primary control level can't make a rapid and complete response to any load changes. So, in order to have a better power quality, Researchers need the secondary control level. In the connection point between the grid and microgrid, the bidirectional converter adopts vector decoupling control strategy with double closed loop for PWM to solve the proble m of bidirectional power flow with the grid [22-23]. Fig. 5 and Fig. 6 show the control principle of bidirectional AC-DC converter.

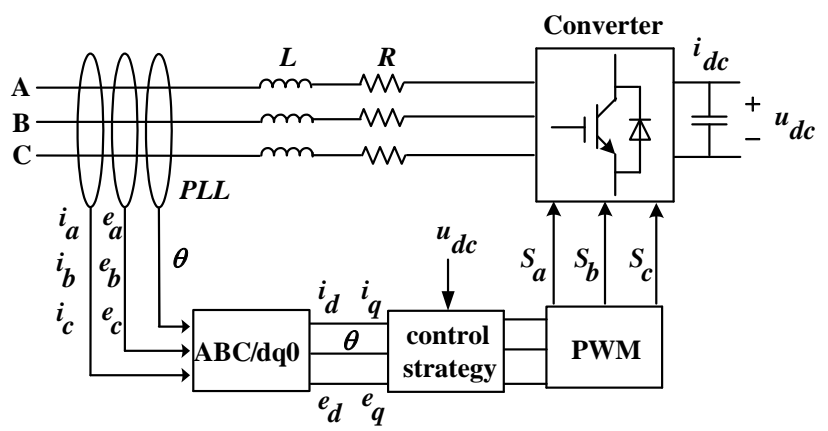

Figure 5. Diagram of bidirectional AC/DC converter

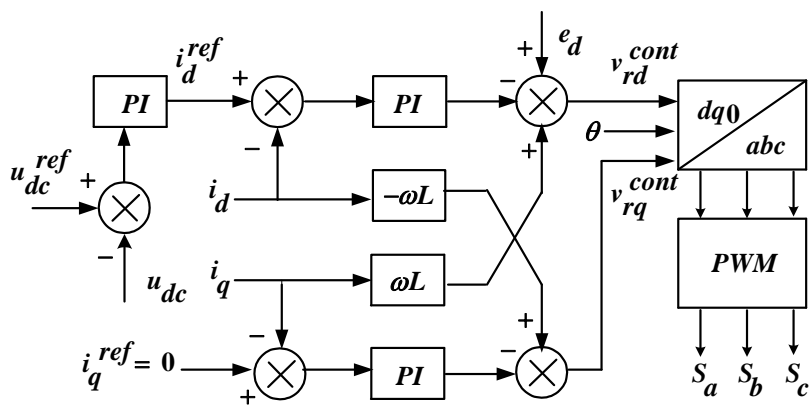

Figure 6. Vector control principle diagram 
As can be seen, Fig. 5 is the control structure diagram of bidirectional AC-DC converter. Where $\mathrm{L}$ is the AC side inductance, ia, ib, ic and ea, eb, ec respectively for the $\mathrm{AC}$ side voltage and current, udc and idc for DC side voltage and current. Fig. 6 is a double closed-loop vector control principle diagram. Where iqref is the $\mathrm{q}$ axis current reference value, and udcref is the DC bus voltage reference value. And the PWM signals are used to control the DC side voltage. In order to meet the need of PWM control, the Park transform is used to change three-phase voltage and current signals into twophase $d-q$ coordinatesignals. At the same time, phase locked loop is sued to meet the the same frequency and phase between invertercurrent and AC side current. Suppose the three-phase voltage is symmetrical in the system, then

$$
\begin{gathered}
e_{a}=E_{m} \cos (\omega t) \\
e_{b}=E_{m} \cos \left(\omega t-\frac{2}{3} \pi\right) \\
e_{c}=E_{m} \cos \left(\omega t+\frac{2}{3} \pi\right)
\end{gathered}
$$

Where, $E_{\mathrm{m}}$ and $\omega$ are respectively the phase voltage and frequency. According to Fig. 5 and Fig. 6, then

$$
\begin{aligned}
& e=R i+L i+u_{r} \\
& C \dot{u}_{d c}=i_{d c}-i_{R}
\end{aligned}
$$

The Park equivalent transform changed the three-phase static coordinate to two-phase stationary coordinate system. At the same time, the d axis was supposed coinciding with the voltage vector. Researchers get the current equations in rotating coordinates.

$$
\begin{gathered}
L \dot{i}_{d}=-R i_{d}+\omega L i_{q}+e_{d}-u_{d c} \\
L \dot{i}_{q}=-R i_{q}+\omega L i_{d}-u_{d c}
\end{gathered}
$$

In the d-q coordinate system, the active power is only related to id, called active current, and reactive power is only related to iq, called the reactive current. DC voltage can be controlled by the active current and the power factor controlled by the reactive current. Therefore, PWM inverter adopt double closed-loop control in the synchronous rotating coordinate, which can achieve the bidirectional power flow between the DC side and AC side with high efficiency and high stability.

Therefore, when the voltage drops or the voltage is instable at the primary control level, the second control level can quickly achieve the purpose of power supply or external delivery, to support the voltage of DC bus.

\section{RESULTS}

In order to testify the control system, a DC microgrid model was established in the Matlab/simulink. In grid-connected mode, the circuit was testified with mutation load.

The solar power generation utilized MPPT control strategy. In order to simulate the output characteristics of the PV array, a plurality of solar battery in parallel were adopted. The inductance of Boost circuit worked in continuous mode. The light intensity $\mathrm{S}=1000 \mathrm{~W} / \mathrm{m}^{2}$ and temperature $\mathrm{T}=28{ }^{\circ} \mathrm{C}$ were selected as the external standard conditions for the simulation. To testify the control strategy, during the time of $3.5 \mathrm{~s}$ to $4 \mathrm{~s}$ and $6.5 \mathrm{~s}$ to $7 \mathrm{~s}$, and the light intensity $\mathrm{S}$ was set independently as $1300 \mathrm{~W} / \mathrm{m}^{2}$ and $700 \mathrm{~W} / \mathrm{m}^{2}$. Fig. 7 showed the output power of the PV array. As can be seen, the control strategy realized the function of MPPT.

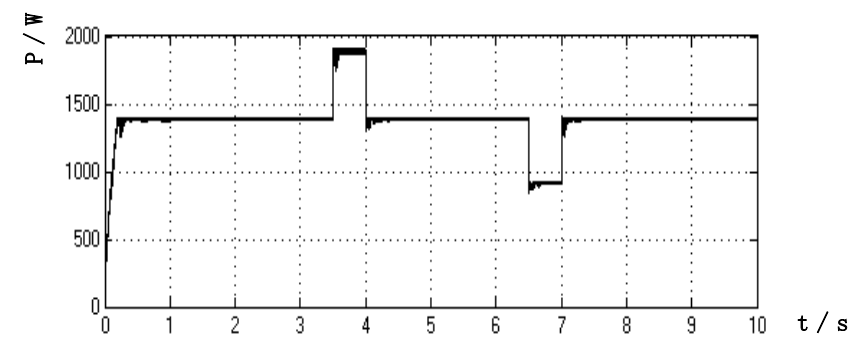

Figure 7. The PV array output power with MPPT control

In the battery simulation circuit, the energy storage inductance L1 is required to be big enough to ensure that the circuit can work normally in the current continuous state, and ensure the battery's charge and discharge in a safe condition.

According to Fig. 3 to build the simulation model, the load in 1-3 seconds for $45 \mathrm{~kW}$, at the third seconds the load reduces to $22.5 \mathrm{~kW}$, and the fifth seconds the load increases to $67.5 \mathrm{~kW}$. The battery connects to the system respectively at 4 seconds and 6 seconds.

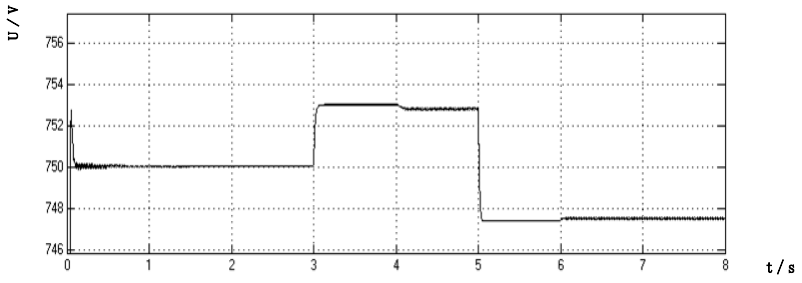

Figure 8 . The DC bus voltage

Researchers can see from simulation results. When the DC bus voltage is greater than the given voltage, the battery is charged, and when the DC bus voltage is less than a given voltage, the battery is discharged to maintain stability of the bus voltage. When the load sudden increases or reduces, the DC bus voltage has fluctuations in response, and the battery voltage stabilizing control has the functions of reduction amplitude and support the bus voltage.

In system simulation, 84 solar panels in parallel, each for $200 \mathrm{~W}$, simulated the output characteristic of solar array. The system got the maximum output power of $16.8 \mathrm{~kW}$ with the control mode of MPPT. The inductance in boost circuit worked in continuous mode. The energy storage capacity is $1700 \mathrm{kWh}$. The average load was $30 \mathrm{~kW}$ at the beginning. After $3 \mathrm{~s}$, the average load reduced to $15 \mathrm{~kW}$. 


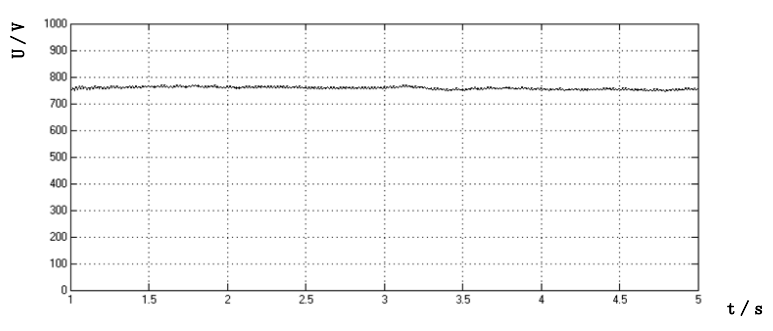

Figure 9. The voltage waveform of DC bus

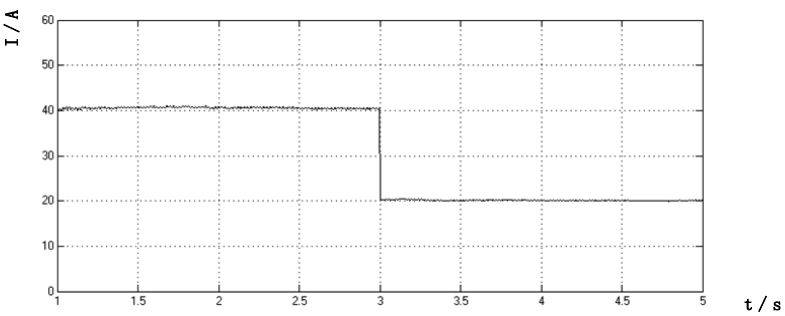

Figure 10. The current waveform of DC bus

Fig. 9 and Fig. 10 showed the voltage and current waveform of DC bus. As can be seen, when the load was $30 \mathrm{~kW}$, the energy storage system in the primary control level quickly discharged to maintain the DC bus voltage. At the same time there still had power shortage, then power of the grid flowed to the microgrid through the bidirectional AC/DC converter by the Secondary control level.

When the load reduced to $15 \mathrm{~kW}$ suddenly, the microgrid began to charging the energy storage system, and the surplus power flow to the grid through the bidirectional A C/DC converter. During the process of load mutation, the $750 \mathrm{~V}$ bus voltage is to maintain basically stable. In order to meet the demand of changing load, bus current followed the change.

\section{CONCLUSIONS}

A hierarchical control strategy for DC microgrid system is proposed. In the primary control level, distributed generations are controlled by the maximum power tracking strategy, and the hybrid energy storage system us es droop control strategy to stabilize DC bus voltage. As the influence of the capacity and natural factors, the first layer control cannot achieve the rapid and complete response to any load changes. Therefore, in the second control layer, at the connection point between the grid and microgrid, the bidirectional converter uses vector decoupling control strategy with double closed loop for pulse width modulation (PWM) to solve the problem of bidirectional power flow with the grid, and gets better power quality.

Researchers can see from the simulation, the system can provide high quality of electric energy and maintain efficient, energy saving, stable operation even in the case of load mutation and distributed power switching. These conclusions provide a reference for the construction of the DC microgrid.

\section{REFERENCES}

[1] L. Zongxiang, W. Caixia, M. Yong, "Over view on microgrid research," Automation of Electric Power System, vol. 31, 2007, pp. 100-107.

[2] W. Chengshan, W. Shouxiang, "Study on some key problems related to distributed generation systems," Aut omation of Electric Power System, vol. 32, 2008, pp. 1-4.

[3] R.H. Lasseter, " Microgrids: distributed power generation," Proc. IEEE Symp. Power Engineering Society Winter Meeting, IEEE Press, Columbus, OH, USA, 2001.

[4] C. Marnay, F.J. Robio, and A.S. Siddiqui, "Shape of the microgrid," Proc. IEEE Symp. Power Engineering Society Winter Meeting, IEEE Press, Columbus, OH, USA, 2001.

[5] M. Barnes, G. Ventakaramanan, J. ondoh, "Real - world microgrids ," Proceedings of the System of Systems Engineering, vol. 4, 2007, pp. 16-18.

[6] T. Funabashi, R. Yokoyama, "Microgrid field test ex-periences in Japan," Proc. IEEE Symp. Power Engineering Society General Meeting, IEEE Press, Canada, 2006, pp.18-22.

[7] N. Hatziargyriou, H. AsanoS, R. Iravani, "Mi-crogrids: An overview of ongoing research, development, and demonstration projects ," IEEE Power \& Energy Magazine, vol. 5, 2007, pp. 7894.

[8] T. Ise, " Advantages and circuit configuration of a DC mi-crogrid," Proc. IEEE Symp. Montreal 2006 Symposium on Microgrids, IEEE Press, Montreal, Canada, 2006, pp. 1-20.

[9] J. Yang, A. Qian, and X. Da, "Research on co-developmental trend of distributed generation and smart grid," Power System Technology, vol. 34: 2010, pp.15-23.

[10] L. Zongxiang, W. Caixia, and M. Yong, "Over view on microgrid research," Automation of Electric Power System, vol. 31: 2007, pp.100-107.

[11] W. Chengshan, W. Shouxiang, "Study on some key problems related to distributed generation systems," Aut omation of Electric Power System, vol. 32: 2008, pp.1-4.

[12] K. Shenai, k. Shah, " Smart DC Micro-grid for Efficient Utilization of Distributed Renewable Energy," Energy Tech, 2011,pp.1-6.

[13] R.H. Lasseter, " Microgrids: distributed power generation," Proc. IEEE Symp. Power Engineering Society Winter Meeting, IEEE Press, Columbus, OH, USA, 2001.

[14] C. Marnay, F.J. Robio, and A.S. Siddiqui, " Shape of the microgrid," Proc. IEEE Symp. Power Engineering Society Winter Meeting, IEEE Press, Columbus, OH, USA, 2001.

[15] W. Weimin, H. Yuanbin, G. Pan, Q. Zhaoming, and W. Yousheng, "Key technologies for DC micro-grids," Transactions of China Electrotechnical Society, vol. 27: 2012, pp.98-113.

[16] D. Salomonsson, S. Lennart S, “ An adaptive control system for a DC microgrid for data centers," Transactions on Industry Applications, vol.44:2008, pp. 1910.

[17] M. Josep, J.C.V. Guerrero, “ Hierarchical control of droopcontrolled AC and DC microgrids a general approach toward standardization," IEEE T ransactions on Industrial Electronics, vol. 58: 2011,pp. 158.

[18] S. John, D. Richard, D.R. Simon D R, “ DC-bus signaling a distributed control strategy for a hybrid renewable nanogrid," IEEE Transactions on Industrial Electronics, vol. 53: 2006, pp. 14531460.

[19] Bryan J, Duke R, Round S. Decentralized generat or scheduling in a nanogrid using DC bus signaling $[\mathrm{J}]$. Australian Journal of Electrical \& Electronics Engineering, 2005, 2( 3) : 183-190.

[20] H. Hua, W.Shan, X. Xiang, and G. Deqiang, "Computing the maximum penetration level of multiple distributed generators in distribution network taking into account voltage regulation constraints," Chinese Society of Electrical Engineering, vol. 26, no. 19, 2006, pp. 13-17.

[21] Q. Kejun, Y. Yue, S. Xiaodan, Z. Chengke, and J. Ping, "Environmental benefits analysis of distributed generation," Chinese Society of Electrical Engineering, vol. 28, no. 29, 2008, pp. $11-15$.

[22] R.A. Ferreira, H.A. Braga, A.A. Ferreira, and P.G. Barbosa, "Analysis of voltage droop control method for dc microgrids with 
Simulink: Modelling and simulation," Proc. IEEE Symp. Industry Applications, IEEE Press, Fortaleza, 5-7 Nov.2012,pp.1-6.

[23] J.M. Guerrero, J.C. Vasquez, J. Matas, L.G. de Vicuña, and M. Castilla, "Hierarchical control of droop-controlled AC and DC microgrids - a general approach toward standardization," Industrial Electronics, IEEE Transact ions on, vol. 58, no. 1, 2011, pp. $158-172$. 